\title{
Scrum with the Spices of Agile Family: A Systematic Mapping
}

\author{
Sara Ashraf, Shabib Aftab \\ Department of Computer Science, Virtual University of Pakistan \\ E-mail: \{sara22.ashraf, shabib.aftab\}@gmail.com
}

Received: 29 July 2017; Accepted: 14 August 2017; Published: 08 November 2017

\begin{abstract}
Agile mania has revolutionized the software industry. Scrum, being a widely adopted mainstream production process, has dominated other Agile family members. Both industrial and academic researchers eagerly tailored and adapted the Scrum framework in quest of software process improvement. Their burning desire for innovation drive them to integrate other software development models with it to leverage the forte of all the models combined and stifle the weaknesses. This paper aims at providing state-of-the-art insightful understanding of how practices from different Agile process models have been plugged into the Scrum framework to bring about improvements in different extents of development that ensued enhanced productivity, and product quality. To gain the in-depth perception, a systematic mapping study has been planned. This study will identify researches on hybrid models of Scrum within agile family, published between 2011 and 2017. Subsequently, these hybrid models of Scrum will be examined broadly by classifying and thematically analyzing the literature, and outcomes will be presented. This study will contribute a latest coarse-grained overview that in turn may guide researchers for future research endeavors.
\end{abstract}

Index Terms-Agile Scrum, Hybrid Scrum, Systematic Mapping Study, Agile Practices, Scrum integrations, Review

\section{INTRODUCTION}

Agile approaches have turned into a tempting option for organizations striving to enhance their performance. They offer a diverse process development ecosystem [1], [7] embodying Agile manifesto [2] [3]. Scrum [8], Testdriven development (TDD) [9], Feature Driven Development (FDD) [10], Extreme Programming (XP) [11], Dynamic Systems Development Method (DSDM) [12] and Crystal methods are all Agile family. By delivering quality product, improving customer satisfaction, and accelerating development process, Agile methodologies fulfil the practitioners' needs [4] [5].

According to [13], the most popular model among Agile family is Scrum. Cardozo et al. [24] conducted a study to prove that Scrum increases productivity. At Microsoft, the most desired development approach was found to be Scrum [14]. And, demographically, the most adopted model is also Scrum [43]. By offering a comprehensive range of management practices [8] [44], Scrum has established its worth in software industry. Meanwhile, it doesn't define the development practices explicitly, thereby, offering researchers an opportunity to adopt and/or adapt practices from other models. Same is the case with other Agile models, that is, exhibiting strong characteristics in some areas, while, lagging behind in others.

With the increasing uncertainty, fast-paced changing technology, and rising customer demands, it is harder for an organization to strictly adhere or follow a specific development methodology. Studies [15], [16] revealed this fact that using an Agile process model in its 'pure' form, doesn't happen often.

Developing a hybrid approach is not a newly sprouted idea in the field of software engineering. A 'Hybrid' approach refers to a phenomenon of combining two or more different methodologies for the purpose of creating a new and better one. Hybrid methodologies for software development acknowledge the fluidity of project management as well as take into account a defter and nuanced way to deal with the development. Researchers believe that these hybrids are an attempt to address numerous challenges like, balancing between development and management, or applying standards by, meanwhile, retaining maximum flexibility [17].

The process models under consideration are hybrid models of Scrum within Agile family. Hybrid models excluding Agile are beyond the domain of our current study [6]. Researchers tried different fusions of Scrum and Agile models in their pursuit of increasing the productivity, project visibility and control, product quality, and customer satisfaction, however, pragmatic adoption of these hybrids is limited.

The paper in hand, presents a comprehensive analysis of the Agile hybrid models of Scrum, such that Section II presents some related work, the protocol for Systematic Mapping Study (SMS) is established in Section III, Section IV confers the results in detail, and Section V concludes the paper. 


\section{RELATED WORK}

In software engineering, Agile software development is relatively a new domain. Despite the availability of a huge volume of researches on Agile, scientific studies with quantitative evidence are merely scarce for generalizing results [18] [19] [20]. Agile methodologies are not implemented mostly in their full capacity, rather selection of a variety of Agile practices make practitioners achieve their organizational goals [28]. It has been evident that Agile methods tailoring is a recent and hottest trend, and has been growing with acceptance and adoption of Agile in industry [21].

Various challenges in Scrum adoption were reported by López-Martínez et al. [25]. Diebold and Dahlem [26] investigated different agile practices popular in software industry under different domains and context. Ashraf and Aftab [27] explored how Scrum framework has been tailored and transformed by adopting and adapting different agile practices. Researchers combined agile approaches and introduced hybrids to achieve lean and agile characteristics [29] [30].

West et al. [22] predicted that hybrid software development approaches will become the standard. Later, this claim was confirmed by Theocharis et al. [23] through a systematic review. Kuhrmann et al. [17] conducted a survey on hybrid approaches for software development and found that they have become mainstream, also, their adoption in industry is irrespective of the organization size and industry sector. Raval and Rathod [31] inferred through an empirical study that hybrid models for software development are way better than traditional models as well as pure Agile models. Moreover, they claimed that better customer satisfaction, risk identification, minimum time to market, reduced cost, and complexity can be achieved by enforcing hybrid theory. Pragmatism, experience, and learning are the vital factors that have driven the evolution that ensued hybrid methodologies for software development [17].

It can be seen that researchers have shed light on the phenomenon of hybrid in context of agile and non-agile paradigm of software development, but no study has specifically investigated the hybrids of Scrum. This SMS fills the gap in the hybrid methodologies within the Agile family, adopted or practiced to improve the Scrum.

\section{RESEARCH METHOD}

According to [32], [33] systematic mapping study is meant for identifying research gaps, collecting evidences to direct future research, and achieving a comprehensive overview on a certain area of exploration. A systematic mapping study is employed mostly in 2 cases:

i) For the research areas having too little empirical evidence,

ii) For the research areas, which are too broad.
A Systematic Mapping Study (SMS) is perceived as an alternative to SLR, provides a coarse-grained overview of the pertinent research area [32].

Considering the principles and guidelines presented by Petersen et al. [34] for SMS in SE, we outlined a research protocol to conduct our SMS. The important steps of our SMS are: i) formulation of research questions QAs, ii) Query string development by identifying keywords, iii) establishing inclusion/ exclusion criteria, iv) screening of articles by applying these selection criteria, v) quality assessment of selected primary studies, vi) Data extraction and process of mapping, and finally, vii) representing the outcome as a systematic map, as shown in fig. 1.

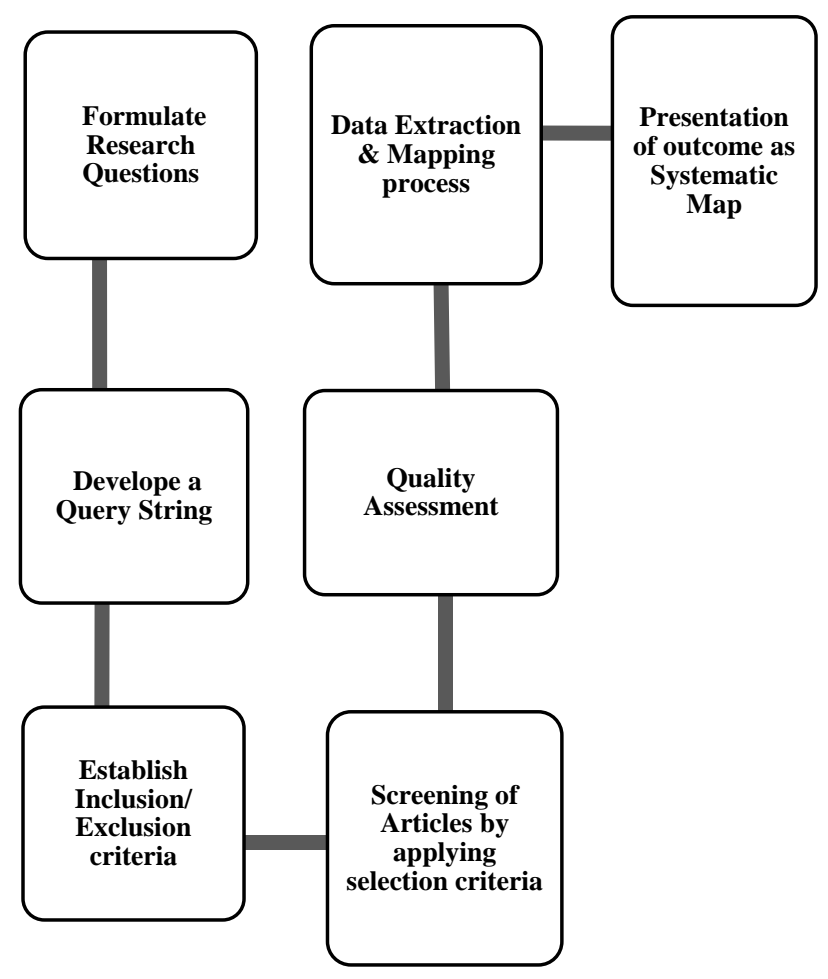

Fig.1. Steps of SMS

\section{A. Research Questions}

The procedure of SMS begins with the formulation of research objectives. These research objectives actually drive the whole investigation process. Following are the Research Questions (RQ) describing the objectives of our study which are:

- RQ1: Which agile models can be integrated with the Scrum process model?

- RQ2: Which practices can be incorporated into Scrum from other models?

- RQ3: How different development methodologies are combined?

- RQ4: What goal/ objectives that have been achieved through these hybrid models? 


\section{B. Search Strategy and Query String}

The search strategy is meant for the identification of candidate primary studies. The final set of primary studies may include or exclude these candidate studies. The search strategy included both automated search as well as a manual search to calibrate the search string and to ensure the process accuracy.

Initially, an ad hoc search was performed that helped finding relevant keywords. Similarly, the research questions helped in refining the keywords further. These keywords were connected using conjunction (AND) and disjunction (OR) Boolean operators. Following query string was formed:

(hybrid AND (agile OR scrum) AND (process OR model OR framework OR method) OR (integrating OR combining OR blending) AND (scrum AND (XP OR "extreme programming" OR TDD OR "test driven development" OR FDD OR feature driven development OR kanban OR crystal)))

The above query was executed on Google Scholar to find the most appropriate and most relevant research material.

\section{Selection Criteria}

Related literature was extracted through applying all the inclusion criteria and exclusion criteria. For an article to be included, all the inclusion criteria should be satisfied. At least one of the exclusion criteria ought to be met to get excluded, from final set.

\section{1) Inclusion Criteria (IC):}

Following propositions describe the inclusion criteria specified for selection of material:

- IC1: Articles available in workshops, proceedings of conferences, journals, and conferences.

- IC2: Articles published in peer-reviewed journals.

- IC3: Articles having clear focus on hybrid models of Scrum.

- IC4: Articles or literature published between 2011 and 2017.

\section{2) Exclusion Criteria (EC):}

Following propositions describe the specified exclusion criteria:

- EC1: Articles not available in English.

- EC2: Literature published in non-peer reviewed publications.

- EC3: Informal literature i.e. thesis, dissertations, book chapters, tutorials, etc.

- EC4: Articles under peer review, or unpublished.

- EC5: Articles for which full-text can't be downloaded.

- EC6: Articles on agile hybrid models but Scrum not included.

- EC7: Articles including lessons learned, recommendations, and/or without appendixes.

- EC8: Articles based on tools introduced in hybrid environment.
- EC9: Articles including variants of Scrum without integrating it with any other process models.

- EC10: Articles including SLRs, SMS on hybrid agile process models.

- EC11: Articles including Scrum hybrids but underlying methodology is not comprehensively elaborated.

- EC12: Articles that include empirical studies of hybrid Scrum in other disciplines.

A preliminary search based on keywords displayed a huge amount of papers and other literature i.e. a gross of 2490. For refining the automated search further, the above-mentioned selection criteria were applied that filtered out the literature irrelevant with respect to our research questions. All the steps of this selection procedure can be seen in fig. 2. Along with the automated search, carried out through applying different filters, a manual search was also performed using backward snowballing [35].

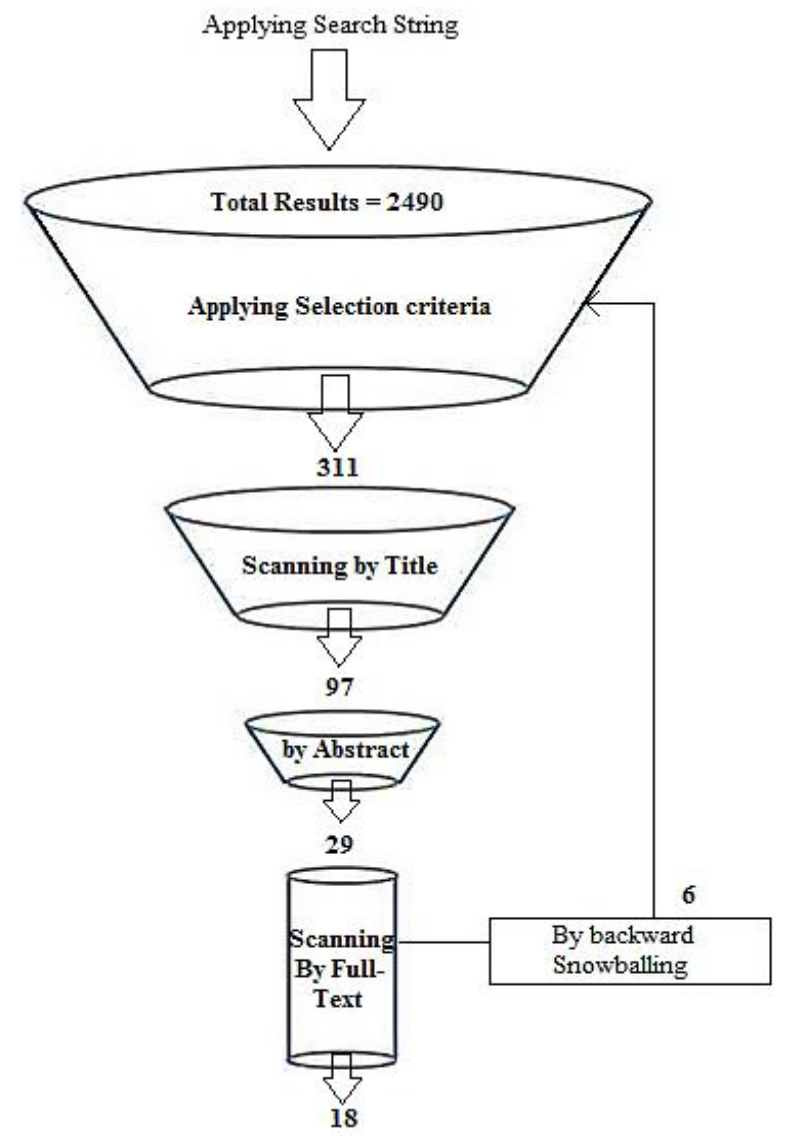

Fig.2. Search process

\section{Quality Assessment}

The entire systematic mapping study relies on the literature that has been acquired through a sophisticated search procedure. Therefore, there must be some explicit criteria to validate the quality of that literature, selected as candidate articles. Thus, to make the findings more effective, the quality assessment criteria were established. 
A manual inspection has been carried out for each selected article by going through its title, abstract, and/or conclusions. Each article has been assessed against a set of questions, specified w.r.t. the quality of reporting, the research design described and used in it. It ensures that each selected article is of adequate standard. Following checklist describes the criteria to assess the quality of primary studies, shown in Table 1 .
Item QA1 is taken from the work of [36], QA2 and QA5 are based on the work of [5]. QA3 demands the empirical evidence w.r.t. its rigor and relevance [37]. A threshold of score 2.0 has been set for the inclusion of an article, because QA1 for recently published articles, QA3 for proposals, and QA 5 might be assigned a zero score.

Table 1. Criteria for Quality Assessment

\begin{tabular}{|c|c|c|c|c|c|}
\hline Item & Statement & $\begin{array}{l}\text { Yes } \\
1.0\end{array}$ & $\begin{array}{c}\text { Partially } \\
0.5\end{array}$ & $\begin{array}{c}\text { No } \\
\text { 0 }\end{array}$ & Descriptions \\
\hline QA1 & Has the article been cited by other researchers? & & & & $\begin{array}{c}\text { Cited by } 4 \text { or above/ cited by } 3 \text { or less? Cited } \\
\text { by no one }\end{array}$ \\
\hline QA2 & Is goal /objective of the study clearly stated? & & & & Yes/ Not clearly stated/ Not stated \\
\hline QA3 & $\begin{array}{l}\text { Do the article has provided with any evidence? i.e. idea is } \\
\text { validated? }\end{array}$ & & & & $\begin{array}{l}\text { By a case-study/ only parts of idea are } \\
\text { validated/ not validated }\end{array}$ \\
\hline QA4 & Is there any personal viewpoint of the author? & & & & $\begin{array}{c}\text { Yes/ paper describes a specific context/ Paper } \\
\text { is research-based }\end{array}$ \\
\hline QA5 & Does the article elaborate the idea in detail? & & & & Yes/ needs more detail/ idea is abstract \\
\hline
\end{tabular}

\section{E. Data Extraction \& Mapping}

After qualifying the criteria specified for quality assessment, a final set of primary studies comprising of 18 papers has been derived. Data to be extracted from this set of studies should be in compliance with the research questions as formulated in the first step of research protocol. We recorded the extracted data items as listed in Table 2 on a spreadsheet.

Table 2. Data Extraction Format

\begin{tabular}{|c|c|c|}
\hline Sr. \# & Description & Details \\
\hline \multicolumn{3}{|c|}{ General Information } \\
\hline 1. & Bibliographic Details & $\begin{array}{c}\text { Author, number of citations, } \\
\text { publication year, source, article type } \\
\text { (journal, conference, workshop) }\end{array}$ \\
\hline \multicolumn{3}{|c|}{$\begin{array}{c}\text { Extraction of Data } \\
\text { (Quantitative Results of Study) }\end{array}$} \\
\hline 2. & Quality Score & As calculated through QA criteria \\
\hline 3. & Model & Model title/ name \\
\hline 4. & Research type & $\begin{array}{c}\text { (validation, solution proposal, } \\
\text { philosophical, evaluation, opinion, or } \\
\text { experience) }\end{array}$ \\
\hline 5. & Contribution type & $\begin{array}{l}\text { (Tool, model/ framework, process/ } \\
\text { method, measurement) }\end{array}$ \\
\hline \multicolumn{3}{|c|}{$\begin{array}{c}\text { Mapping of Data } \\
\text { (Qualitative Results of Study) }\end{array}$} \\
\hline 6. & Models integrated & Model names \& Description \\
\hline 7. & Practices adopted & $\begin{array}{c}\text { For each model that is integrated into } \\
\text { the new model: } \\
\text { Roles/ events / Artifacts/ phases }\end{array}$ \\
\hline 8. & Practices adapted/ excluded & $\begin{array}{c}\text { For each model that is included into } \\
\text { the new model: } \\
\text { Roles/ events / Artifacts/ phases }\end{array}$ \\
\hline 9. & Goal/ Areas addressed & $\begin{array}{c}\text { Identification of Areas where } \\
\text { improvements are made. }\end{array}$ \\
\hline 10. & Limitations/ challenges & Weaknesses of study, if any \\
\hline
\end{tabular}

\section{RESULTS}

By following the research procedure as described in fig. 1 , a set of primary studies containing 18 peer-reviewed articles, published in different journals and conferences between 2011- 2017, were found (see in Appendix A).

\section{A. Quality Score}

The quality score of a literature may identify the potential limitations of that research [32]. Likewise, reliability of the findings of SMS and quality of the selected literature is reflected through their quality scores [38].

The selected articles were evaluated against the criteria set for quality assessment. The evaluation results are presented in fig. 3 .

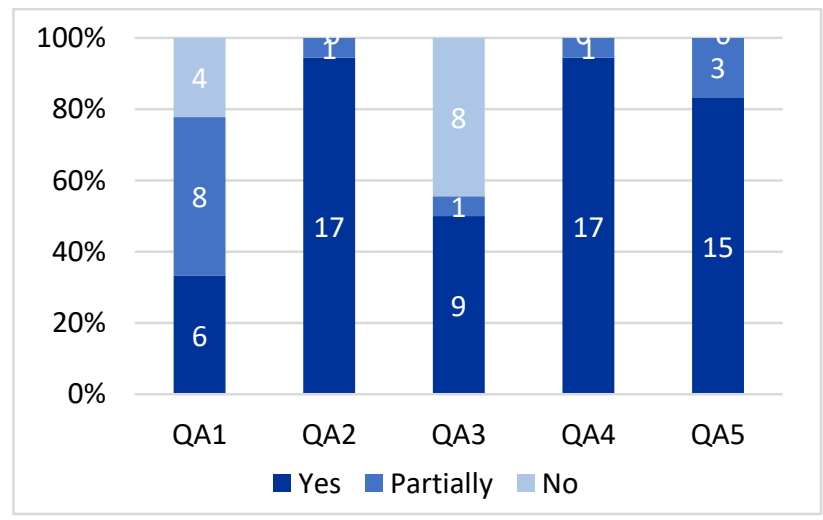

Fig.3. Distribution of publications over Quality Score

For QA1, Google Scholar has been consulted to find number of citations for a paper, 6 papers have 4 or above, 8 papers have between 1 and 4 , while 4 have zero citation which are published in 2016 onwards. For QA2, 17 papers have clearly stated objective/ goal, only 1 paper 
has vague statement. For QA3, there is only one article presenting evidence from expert opinions rather than a case-study, so considered as partial. For QA4, all papers have detailed description of their frameworks except 1 with a little detail. All the papers obtained less than the threshold score set for disqualification.

\section{B. Classification of Literature}

To comprehend the crucial results from pertinent studies, the literature under consideration is classified into different categories based on 5 major dimensions: i) publication channel type, ii) research type, iii) by year, iv) contribution type, and v) research focus [34].

\section{1) By Publication Channel Type}

As far as the type of publication channel is concerned, our selected literature mainly belongs to scientific journals, and conference proceedings. Out of 18 articles, $83 \%$ (15) articles were published in journals, whereas, only $17 \%$ (3) appeared in conference proceedings. Distribution of articles by publication channel is presented in Table 3.

Table 3. Distribution of Articles by Publication Channel Type

\begin{tabular}{|c|c|c|c|}
\hline $\begin{array}{c}\text { Sr. } \\
\#\end{array}$ & Selected Research Works & Type & $\begin{array}{c}\text { No. of } \\
\text { Researches }\end{array}$ \\
\hline 1. & $\begin{array}{c}{[\mathrm{P} 1][\mathrm{P} 2][\mathrm{P} 3][\mathrm{P} 4][\mathrm{P} 5]} \\
{[\mathrm{P} 6][\mathrm{P} 7][\mathrm{P} 8][\mathrm{P} 10][\mathrm{P} 11]} \\
{[\mathrm{P} 12][\mathrm{P} 13][\mathrm{P} 14][\mathrm{P} 17]} \\
{[\mathrm{P} 18]}\end{array}$ & $\mathrm{J}$ & 15 \\
\hline 2. & [P9] [P15] [P16] & $\mathrm{C}$ & 3 \\
\hline 3. & ---- & $\mathrm{W}$ & -- \\
\hline
\end{tabular}

\section{2) By Publication Research Type}

Research can be classified into 2 major classes: i) empirical, and ii) non-empirical. These 2 classes are further divided into 6 categories as described by Wieringa et al. [39]: i) evaluation research, ii) validation research, (for empirical) iii) experience papers, iv) opinion papers, v) conceptual proposals, and vi) solution proposals (for non-empirical). We followed this classification for our research as shown in Table 5. Fig. 4 presents the distribution of publications over research type.

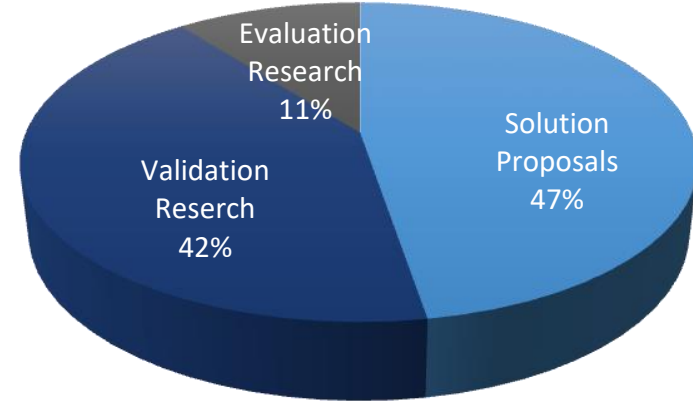

Fig.4. Distribution of publications over Research Type

\section{3) By Publication Year}

Temporal distribution of publications is shown in Fig. 5 .

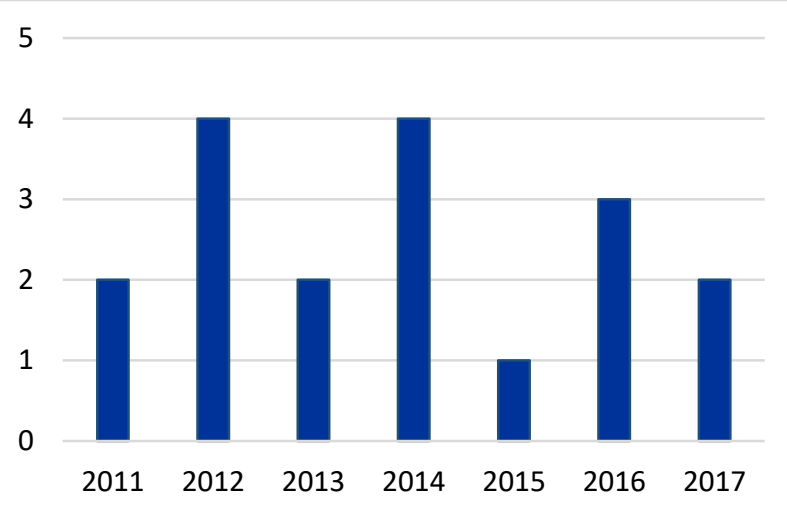

Fig.5. Distribution of publications over Research Type

\section{4) By Publication Contribution Type}

We found 5 categories to classify the selected publications by contribution type: Metric, Model/ Framework, Tool, Method/ Process, and Open Items. We included models and methods only, rest of them are beyond the domain of our research. Table 5 presents the results for contribution type.

\section{5) By Publication Focus}

Classification scheme established for our SMS specifies that each article spans 2 major research foci:

i) By Agile models that are integrated with Scrum process model.

ii) By practices they adopted in the hybrid model.

Table 4 and Table 6 present the studies by (i) and (ii) focus respectively. Table 6 is a descriptive representation. Table 4, 5 and 6 answer the RQ1.

Table 4. Distribution of Articles by Agile Models integrated with Scrum

\begin{tabular}{|c|c|c|c|c|c|c|}
\hline & \multicolumn{5}{|c|}{ Scrum Model integrated with } \\
\hline Year & XP & DSDM & FDD & TDD & Kanban & RUP \\
\hline 2011 & {$[\mathrm{P} 1][\mathrm{P} 2]$} & & & & & \\
\hline 2012 & $\begin{array}{c}{[\mathrm{P} 3][\mathrm{P} 4]} \\
{[\mathrm{P} 5][\mathrm{P} 6]}\end{array}$ & & & & & [P3] [P5] \\
\hline 2013 & {$[\mathrm{P} 7][\mathrm{P} 8]$} & & & & & \\
\hline 2014 & $\begin{array}{c}{[\mathrm{P} 9][\mathrm{P} 10]} \\
{[\mathrm{P} 11][\mathrm{P} 12]}\end{array}$ & {$[\mathrm{P} 11]$} & & & & {$[\mathrm{P} 12]$} \\
\hline 2015 & & & {$[\mathrm{P} 13]$} & & & \\
\hline 2016 & {$[\mathrm{P} 16]$} & {$[\mathrm{P} 16]$} & {$[\mathrm{P} 14]$} & {$[\mathrm{P} 15]$} & & \\
\hline 2017 & {$[\mathrm{P} 17][\mathrm{P} 18]$} & {$[\mathrm{P} 18]$} & & & & {$[\mathrm{P} 17]$} \\
\hline
\end{tabular}

An article may include more than one models combined with Scrum. Fig. 6 presents the number of articles distributed by the Agile models integrated with Scrum. 


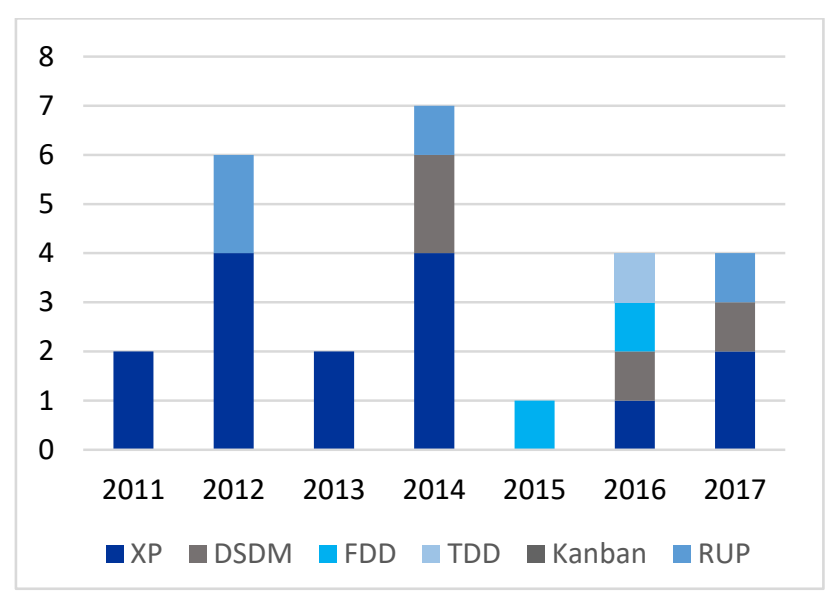

Fig.6. Research focus and Distribution by Agile Model Type
A Systematic map over identified research foci related to hybrid models of Scrum within agile family, distributed over type of research, and publication years is shown in fig. 7. In software development, Kanban has not been generally acknowledged [42]. It can be seen in fig. 7 that there is no or rare evidence of researches integrating Scrum with Kanban and Crystal methods.

\section{Discussion}

To find the answers of RQ2, RQ3, and RQ4, we explored the chosen studies thoroughly and depicted the results through diagrams, and also, summarized them by tabular description (see Table 5 and 6).

\section{Mapping}

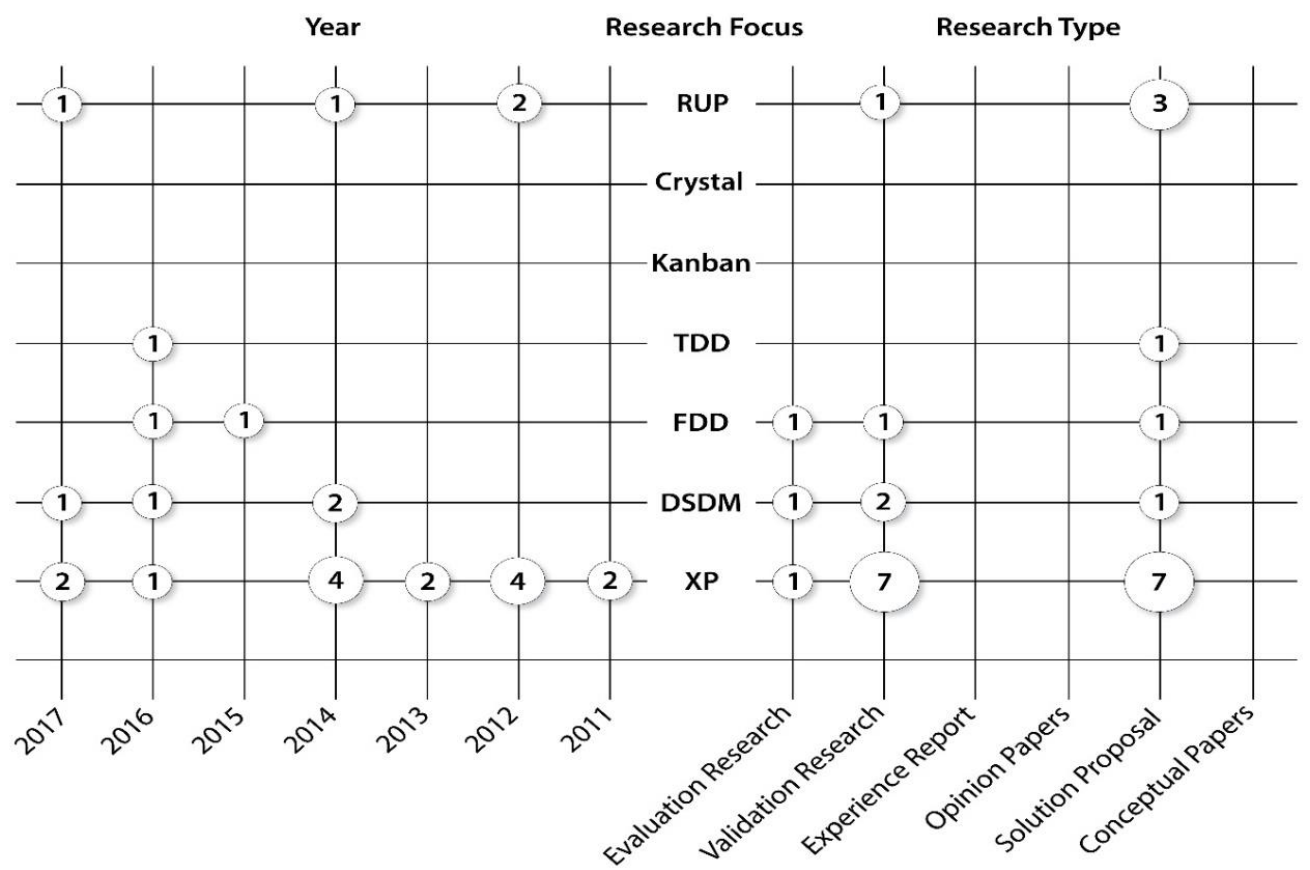

Fig.7. Systematic Map for Distribution of Publications on Scrum Hybrids over Research focus, Research type, and publication Year

Jyothi and Rao [S1] proposed an idea of integrating engineering practices of XP in Scrum and named it as a collaborative and innovative framework. The proposed hybrid model aims at increasing productivity and improving quality and collaboration among team members. The development starts with planning, and establishing the processes and procedures. The framework includes Scrum Sprints, and each Sprint contains various tailored phases of XP i.e. requirements, analysis, design, evolution and delivery phases. XP practices i.e. Refactoring, simple design, pair programming, collective code ownership, and continuous integration, are executed during these phases. By introducing traceability practices into the aforementioned framework, the authors tried to improve the documentation, change management, and overall productivity.

The idea of hybrid framework along with suggested traceability practices needs to be validated at industry.
M. R. J. Qureshi [S2] presented a fine integration of Scrum and XP to meet the challenges that these models confront when employed individually. The author named this integration as eXSCRUM. The model combined the engineering practices of XP with the project management paradigm of Scrum. The novelty of this model was that it didn't compromise the integrity of both models. A PreScrum activity Sprint zero was introduced for which guidelines were presented in detail. The model eXSCRUM executed all the XP practices within Sprint cycle of Scrum. A controlled case study was conducted to validate the model. A Payroll Management System was developed in four iterations with a team of six members. At the beginning of project, a comprehensive training of one week was conducted. The results of this case-study proved that the proposed model overcome the weaknesses of both XP and Scrum. Also, improved product quality, customer involvement and satisfaction. 
Though the soul of both models Scrum and XP was kept alive but executing all the practices of XP in a Sprint cycle is not a feasible idea. Also, a comparative analysis of the three models must be there to show that eXSCRUM is better than these two models when employed individually.

Bashir and Qureshi [S3] presented a hybrid framework aimed at increasing the productivity and producing high quality software for small to medium scale projects. This framework is a fusion of three process models RUP, XP, and Scrum. The authors included 3 phases and 6 logical activities from RUP to establish the structure of framework. Formal procedures of Scrum were remained intact and engineering practices from XP were implemented during different phases and logical activities. The idea of minimal modeling and adequate documentation may help the new systems to manage change efficiently. Similarly, it gives the liberty to choose the suitable practices from XP and RUP according to the given size and nature of the project.

The proposed model needs to be validated in controlled and industrial settings. Although the model gives a formal structure to the whole development process by specifying some phases and activities of RUP, yet, there is a chance of compromising agility due to RUP's heavy-weight nature.

Mushtaq and Qureshi [S4] proposed an extended version of Scrum by integrating it with XP. The proposed hybrid model was intended to deliver high quality software while satisfying stakeholders. The authors tried to enrich the Scrum model's project management with product engineering practices of XP. Execution of Sprint Zero is carried out prior to that of Sprint. The development cycle follows the basic phases of XP i.e. planning phase, designing phase, coding phase, and testing phase. During a Sprint cycle, each user story is designed, implemented, and tested exclusively. Continuous integration is employed subsequently. The working of the proposed model was evaluated through a case-study conducted under controlled scenario with a team of 6 members that have no prior experience of Agile development processes. The team had an introductory session with the practices of the models involved. The study revealed that the hybrid model delivered better software quality, client satisfaction, and productivity.

The proposed hybrid model lacks the guidelines regarding implementation of XP practices. The model doesn't specify any documentation practices. Also, the model needs to be validated in different scenarios to generalize the results.

Nisa and Qureshi [S5] introduced a balanced integration of RUP and XP with Scrum. The authors named this hybrid model as SPRUP. The model was designed in a way to achieve high quality by adapting to changing requirements. The model SPRUP includes 4 phases from RUP (i.e. i) inception ii) Elaboration, iii) Production \& iv) Transition), roles, ceremonies and artifacts from Scrum with slight alterations. Similarly, few practices were added from XP. The proposed model was assessed under controlled situation with a team of 5 .
The case-study was based on developing Hotel Management System, took 4 iterations, and 5 weeks. The team had a training session before getting into project. The experimental results revealed that SPRUP improves the quality, performance, customer satisfaction, and productivity.

The proposed hybrid model doesn't specify which XP practices are included in the model. The RUP model's intensive documentation trend may lead to compromise the agility of the model. Also, the model needs to be validated in comparison with the other 3 models RUP, $\mathrm{XP}$, and Scrum.

Another fine blend of XP and Scrum was IXPRUM. The hybrid model was meant to deliver high quality product and to increase productivity, presented by Aman Ullah et al. [S6]]. The model employs Scrum's practices within the phases of XP i.e. planning, designing, coding, and testing. Each Sprint includes the 4 phases of XP. All the formally described practices of Scrum process model were included in the IXPRUM except few with little modifications. The first iteration begins with the planning of Product backlog. The role of the Scrum Master was adapted as IXPRUM Master. The Product Owner was supposed to attend all the IXPRUM's meetings. To prove the IXPRUM's rationality, a controlled case study was conducted to deliver a library system within 5 weeks. Six team members were engaged to carry out this project. The study proved that the model improves team's productivity and software quality.

The model doesn't provide any clear guidelines about how to integrate XP's engineering practices. . Literature is in detail but the model is abstract. The 1st Sprint begins with the planning of Product backlog that is not cyclic so shouldn't be included in the Sprint. Same case study should be conducted for Scrum and XP in comparison with IXPRUM.

Malhotra and Chug [S7] proposed a fusion of Scrum and XP and named it IXSCRUM. The model was intended to attain customer satisfaction, improved product quality within time and cost constraints. The authors have the same motivation of filling the gap between project management and engineering. To achieve the best of both dimensions they follow all the management practices (including roles, ceremonies, and artifacts) of Scrum strictly, and some roles (i.e. analyst, developer, and tester) and engineering practices (i.e. Testdriven development, unit testing, simple design, and constant refactoring) of XP. The IXSCRUM model was validated through a case study based on a Shopping application. It was a 3-Sprint project, completed in four weeks. According to findings of this case study authors claimed that the product quality was improved and delivered in minimum time.

The model must be evaluated in different practical scenarios. Test-driven development gets more complicated for medium to large-scale projects. Moreover, the results revealed in the given paper were not complete. Such hybrid models' performance must be analyzed in comparison of the models integrated. 
Researchers believe that a high-quality product can only be engineered through following a high-quality process. Jan and Javed [S8] also tried to improve the software development process by blending CMMI level 2 and 3's practices into Scrum and named this effort as SCXTREME. This hybrid approach merges the 8 Process Areas PAs (out of 22) of CMMI, Scrum, and XP model. The selection of Scrum model among other agile models were because of its wide use in Pakistani industry. SCXTREME is based on agile i.e. Scrum and XP practices combined with the CMMI Specific Practices SPs. Configuration management, track and control changes, establishing integrity, and risk management are mostly neglected areas in SCRUM/XP, so SPs of CMMI are added regarding these areas into the proposed model. SCXTREME is easy to implement under limited resources and budget.

The proposed model needs to be validated in small to medium scale organizations. Not all the SPs of level2 can be implemented for any small level project.

To improve team's productivity, code quality, and maintenance process, Sultana et al. [S9] proposed a blend of practices from XP, Scrum, and DSDM. The model was a perfect fusion of project management, product engineering, and configuration management practices. Project initiation activities were elaborated in detail. All the ceremonies, phases, and artifacts were described clearly. Role of technical writer was a new addition for documentation related activities. To explore the potential of hybrid model, a controlled case-study of 6 weeks and 4 iterations, was conducted. It was based on 2 teams each of 8 members, working on 2 projects, following Scrum and hybrid in parallel. Results of comparison revealed improvement in customer satisfaction, quality, and maintenance support.

The proposed model should be validated for medium to large-scale projects.

Enhanced Scrum framework is one of those numerous efforts that have been made by researchers to get the best out of Scrum-XP fusion. Previous efforts introduced this combination with a little guide and direction towards using and applying each of the both models' practices. N.R. Darwish [S10] filled that gap by presenting a set of elaborated guidelines to execute each practice. The author prepared the model in 4 phases: firstly, he outlined the Enhanced Scrum Framework, then, planned a list of guidelines, after that he validated the list of guidelines through expert opinion, and finally, the guidelines were revised in the light of those experts' responses. All the Scrum ceremonies, roles, and artifacts were kept intact, while incorporated some XP practices where they were needed in the Enhanced scrum framework.

The proposed hybrid model must be validated in the field to prove its potential. The model is only feasible for small-scale projects.

Fahad et al. [S11] integrated DSDM and XP with Scrum to achieve the in time and quality product delivery with minimum cost. They named it as DXPRUM. The model employs most of the engineering practices of XP (i.e. user story cards, coding standards, test-driven development, pair programming, refactoring, 40 hours per week work, and collective ownership of code) throughout the seven phases of DSDM model (i.e. preproject, post-project phases, feasibility, design, development, and functional prototype). Similarly, the Scrum's artifacts, ceremonies, and roles are all incorporated with slight modifications. The DXPRUM was validated in a controlled setting in six weeks and four Sprints. The results of the case-study revealed that DXPRUM provides improved quality for medium-scale projects, maximum customer satisfaction and in-time product delivery with reduced cost.

The model needs to be validated in different practical settings so that the results can be generalized further and the model can be improved. The model doesn't provide any detail about requirements elicitation and analysis phase. Training and prior experience for the team is not taken into account. Moreover, the duration of ceremonies adopted from Scrum is elongated in the model, that may affect its agility.

The idea of blending agile models Scrum and XP with non-agile process model RUP was presented by Ahmed et al. [S12] and called it XSR. The hybrid model was meant to deliver high quality product on-time, satisfying business \& customer needs, and to improve team's productivity. XSR borrows 3 phases of RUP i.e. inception, construction, and transition, artifacts i.e. vision document, architectural modeling, and practices like risk assessment, deployment planning etc. Similarly, the proposed model executes the engineering practices of XP i.e. User story cards, coding standards, test-driven development, pair programming, refactoring, collective ownership of code within RUP phases. Moreover, certain Scrum practices are also tailored like Scrum Master role is excluded. Sprints size remain uniform for all Sprints of a project.

The framework doesn't clearly mention which Scrum management practices are included in the model. Despite the fact, that RUP model's phases will provide a structure to the whole development but it seems like RUP dominates the other two models that might compromise the agility of XSR. The model has no practical implications.

US-Scrum, a model proposed by U. Rafi et al. [S13] is more concerned about providing enhanced usability security, and correctness to the web applications by fitting FDD phases into Scrum model. This model ensures quality from the initial phases of product development by involving specialized team led by specialized managers. Specialized managers build product backlog and manage traceability of features (functional, security and usability) using traceability metrics. Selected features are implemented in parallel by the specialized teams in a Sprint. A comprehensive Requirements validation and verification is supported in two steps i.e. in-sprint and after sprint.

Authors have proposed the model but did not provide any implementation level details. On one hand, it reduces the pressure on developers, but at the same time, increases the number of masters or managers, although the same could be done by Scrum Master. 
It has been evident that there is a tradeoff between high quality and on-time delivery for both the Scrum and FDD frameworks. The solution to this problem was proposed by Tirumala et al. [S14]. They enriched the Scrum by incorporating the practices of FDD and called it SCRFDD. The proposed hybrid model is intended to provide high-quality software and timely delivery of the product simultaneously. It focuses on timely releases of independent features. Hierarchical monitoring of Sprint work was introduced. The model SCR-FDD was realized in comparison with Scrum and FDD, in a practical situation based on 3 modules of a large-scale project. There were 3 teams each following Scrum, FDD, and SCR-FDD respectively. The findings justified the model's competence, as it achieved $10 \%$ more customer satisfaction than the Scrum model, better quality, and delivered on-time.

Though, the SCR-FDD mentioned the practices included from both the models, yet, it was more abstract. The proposed model should be validated in on large-scale so that results can be generalized.

Maria et al. [S15] systematically integrated TDD with Scrum to get the benefit of improved software quality based on testing standards along with better project and team management. The authors combined both frameworks in a synchronized and adaptable manner to sustain their individuality. They conducted a comparative analysis comprehensively for both methodologies. While keeping in view the strengths and weaknesses of both TDD and Scrum the authors selected 14 essential characteristics ( 7 practices, 2 roles, and 5 artifacts) of these process models. These characteristics are then incorporated in the hybrid model in a fashion that both process models can coexist without conflicting each other. Moreover, maximum benefit can be gained out of their management and engineering practices. Roles of Developer and Scrum Master are considered most important. The product developed using this model will have minimum defects in code due to continuous testing and feedback that in turn improves product quality and reduces cost and time. The management practices will improve the team's performance and overall development process as well.

The proposed model has not been validated in a practical setting to justify the claimed outcomes. Selection of coordinated practices that lead to coexistence and synchronization of two agile models is a difficult task. A tool should be developed to assist in this regard.

H. M. Tri et al. [S16] conducted a survey. Aim of the appraisal was to collect information regarding Agile methodologies by comprehensive comparison and analysis. Management and engineering practice values were evaluated, and on the basis of the findings, authors proposed a Universal Dynamic System Development Method (UDSDM) and a framework. Three Agile software development methods were combined into it i.e. Scrum, DSDM, and XP. DSDM (Atern) will serve as a framework of controls. Any change in business plan gets immediate response from it. Rest of the practices will be selected from Scrum and XP on demand of context. Scrum will provide management practice values and XP will be responsible for the engineering practice values.

The paper doesn't provide any practical evidence.

To achieve high quality and team productivity for large-scale projects, Darwish and Warad [S17] augmented the most researched Scrum-XP fusion with RUP model. The hybrid model combined the forte of these three models in such a way that could overcome their weaknesses. The integrated framework derives 4 phases of RUP, while, plan, design, code, and test activities from XP, similarly, Scrum roles, ceremonies, and artifacts are contained within. Authors claimed that the proposed framework will improve productivity, customer satisfaction, documentation, consequently, flexible to changes.

The proposed integrated framework seems a fine and balanced blend of Scrum, XP, and RUP. It should be validated for small and large-scale projects to reveal its potential.

An evaluation study, based on comparative analysis of two models, was conducted by Fahad et al. [S18]. One of these model was Agile DSDM, and the other one was DXPRUM [S11]. Both models were appraised through independent case studies in real-project settings, and proved the claim valid that the hybrid model DXPRUM yields better quality, within minimum time, and cost.

Moreover, increases customer satisfaction by providing user friendly model.

\section{E. Threats to validity}

There are a number of threats to the validity of results of this SMS:

a) Coverage of study search: The study search may missed out some relevant literature. For mitigating this threat, we employed both digital and manual search using snowballing [35].

b) Biased study selection: For mitigating this kind of threat, researchers have established exhaustive inclusion/ exclusion criteria. Moreover, to assess rationality of the selected studies, quality assessment criteria were designed under guidelines of different experts [5] [36] [37].

c) Inaccurate data extraction \& synthesis: Data extraction format has been designed inline with the previous renowned researcher's work [40] [41]. However, for data synthesis and mapping there were studies that didn't provide clear description, so, we had to infer some information.

\section{F. Limitations of research}

Our research work has following limitations:

a) Despite all efforts we made, some relevant articles may be missed out.

b) A number of anecdotal evidence on hybrid approaches for software development has been found, still, scientific studies on applications of those hybrids are scarce. 
Table 5. Selected Articles on Hybrid models of Scrum

\begin{tabular}{|c|c|c|c|c|c|c|}
\hline Ref\# & Title & Year & Research Type & $\begin{array}{c}\text { Contribution } \\
\text { Type }\end{array}$ & Models Integrated & Cited by \\
\hline$[\mathrm{S} 1]$ & $\begin{array}{l}\text { Effective Implementation of Agile } \\
\text { Practices Ingenious and Organized } \\
\text { Theoretical Framework }\end{array}$ & 2011 & Solution proposal & Model & Scrum, XP & 8 \\
\hline$[\mathrm{S} 2]$ & $\begin{array}{c}\text { Empirical Evaluation of the Proposed eXSCRUM } \\
\text { Model: Results of a Case Study }\end{array}$ & 2011 & Validation research & Model & Scrum, XP & 5 \\
\hline$[\mathrm{S} 3]$ & $\begin{array}{c}\text { Hybrid Software Development Approach For Small } \\
\text { To Medium Scale Projects: RUP, XP \& Scrum }\end{array}$ & 2012 & Solution proposal & Model & RUP, XP \& Scrum & 16 \\
\hline [S4] & Novel Hybrid Model: Integrating Scrum and XP & 2012 & Validation research & Model & Scrum, XP & 20 \\
\hline [S5] & $\begin{array}{l}\text { Empirical Estimation of Hybrid Model: A } \\
\text { Controlled Case Study }\end{array}$ & 2012 & Validation research & Model & Scrum, XP, RUP & 8 \\
\hline [S6] & $\begin{array}{c}\text { IXPRUM-A Novel Agile Model for Software } \\
\text { Development }\end{array}$ & 2012 & Validation research & Model & Scrum, XP & 3 \\
\hline [S7] & $\begin{array}{c}\text { IXSCRUM-A Framework Combining Scrum and } \\
\text { XP }\end{array}$ & 2013 & Validation research & Model & Scrum, XP & 2 \\
\hline [S8] & $\begin{array}{c}\text { SCXTREME Framework: A Customized Approach } \\
\text { of Process Improvements in Agile Blend with } \\
\text { CMMI Practices in Pakistan }\end{array}$ & 2013 & Solution proposal & Model & Scrum, XP & 3 \\
\hline [S9] & \begin{tabular}{|c|}
$\begin{array}{c}\text { A Hybrid Model by Integrating Agile Practices for } \\
\text { Pakistani Software Industry (IEEE) }\end{array}$ \\
\end{tabular} & 2014 & Validation research & Model & Scrum, XP, DSDM & 9 \\
\hline$[\mathrm{S} 10]$ & $\begin{array}{c}\text { Enhancements In Scrum Framework Using Extreme } \\
\text { Programming Practices }\end{array}$ & 2014 & Solution proposal & Model & Scrum, XP & 3 \\
\hline [S11] & $\begin{array}{l}\text { Software Quality Assurance of Medium Scale } \\
\text { Projects by using DXPRUM Methodology }\end{array}$ & 2014 & Validation research & Model & DSDM, XP, Scrum & 2 \\
\hline [S12] & $\begin{array}{c}\text { XSR: Novel Hybrid Software Development Model } \\
\text { (Integrating XP, Scrum \& RUP) }\end{array}$ & 2014 & Solution proposal & Model & XP, Scrum \& RUP & 4 \\
\hline$[\mathrm{S} 13]$ & $\begin{array}{l}\text { US-Scrum: A Methodology } \\
\text { for Developing Software with Enhanced } \\
\text { Correctness, Usability and Security }\end{array}$ & 2015 & Solution proposal & Model & SCRUM, FDD & 2 \\
\hline$[\mathrm{S} 14]$ & $\begin{array}{l}\text { A Hybrid Agile model using Scrum and Feature } \\
\text { Driven Development }\end{array}$ & 2016 & $\begin{array}{l}\text { Validation research, } \\
\text { Evaluation }\end{array}$ & Model & Scrum, FDD & 1 \\
\hline$[\mathrm{S} 15]$ & $\begin{array}{l}\text { A Synchronous Agile Framework Proposal } \\
\text { Combining Scrum and TDD }\end{array}$ & 2016 & Solution proposal & Model & Scrum, TDD & 0 \\
\hline$[\mathrm{S} 16]$ & $\begin{array}{c}\text { Progress of agile movements in Australia: Propose a } \\
\text { Universal Dynamic System Development Method } \\
\text { (UDSDM) and universal framework. }\end{array}$ & 2016 & Solution proposal & Model & DSDM, XP, Scrum & 0 \\
\hline$[\mathrm{S} 17]$ & $\begin{array}{c}\text { Integrating RUP Approach with Agile Method for } \\
\text { Large Scale Projects }\end{array}$ & 2017 & Solution proposal & Model & Scrum, XP, RUP & 0 \\
\hline$[\mathrm{S} 18]$ & Comparative analysis of DSDM \& DXPRUM & 2017 & Evaluation research & Method & Scrum, XP, DSDM & 0 \\
\hline
\end{tabular}

Table 6. Summary of Selected Studies

\begin{tabular}{|c|c|c|c|}
\hline [S1] & \multicolumn{3}{|c|}{ Effective Implementation of Agile Practices Ingenious and Organized Theoretical Framework } \\
\hline 2011 & SCRUM & $\mathrm{XP}$ & Goal \\
\hline $\begin{array}{c}\text { Practices } \\
\text { adopted }\end{array}$ & $\begin{array}{c}\text { All formal ceremonies, artifacts, \& roles with } \\
\text { minor modifications }\end{array}$ & $\begin{array}{l}\text { Refactoring, simple design, pair programming, } \\
\text { collective code ownership, continuous integration }\end{array}$ & \multirow{2}{*}{$\begin{array}{l}\text { High quality software, } \\
\text { productivity, improved } \\
\text { team communication }\end{array}$} \\
\hline \begin{tabular}{c|} 
Practices \\
excluded/modified
\end{tabular} & Daily Scrum as Planning meeting & Phases of XP are tailored & \\
\hline [S2] & \multicolumn{3}{|c|}{ Empirical Evaluation of the Proposed eXSCRUM Model: Results of a Case Study } \\
\hline 2011 & SCRUM & $\mathrm{XP}$ & Goal \\
\hline $\begin{array}{c}\text { Practices } \\
\text { adopted }\end{array}$ & Follow all formal ceremonies, artifacts, and roles & All practices of XP run in one Sprint cycle & \multirow{2}{*}{$\begin{array}{c}\text { Improved Customer } \\
\text { satisfaction \& } \\
\text { involvement, quality } \\
\text { product } \\
\end{array}$} \\
\hline \begin{tabular}{c|} 
Practices \\
excluded/modified \\
\end{tabular} & Sprint Zero & Phases of XP & \\
\hline [S3] & \multicolumn{3}{|c|}{ Hybrid Software Development Approach for Small to Medium Scale Projects: RUP, XP \& Scrum } \\
\hline
\end{tabular}




\begin{tabular}{|c|c|c|c|c|c|c|c|}
\hline 2012 & \multicolumn{3}{|l|}{ RUP } & \multicolumn{2}{|l|}{ SCRUM } & $\mathrm{XP}$ & Goal \\
\hline $\begin{array}{l}\text { Practices } \\
\text { adopted }\end{array}$ & \multicolumn{3}{|c|}{$\begin{array}{c}3 \text { phases i) domain analysis \& design ii) } \\
\text { Evolution, } \\
\text { iii) Production \& validation } \\
6 \text { logical activities are chosen }\end{array}$} & \multicolumn{2}{|c|}{$\begin{array}{l}\text { All ceremonies are } \\
\text { intact, }\end{array}$} & $\begin{array}{c}\text { Practices included and/or } \\
\text { excluded as per projects' } \\
\text { requirement }\end{array}$ & \multirow{2}{*}{$\begin{array}{c}\text { Increased productivity } \\
\& \text { high quality } \\
\text { software }\end{array}$} \\
\hline $\begin{array}{c}\text { Practices } \\
\text { excluded/modified }\end{array}$ & \multicolumn{3}{|l|}{$\begin{array}{c}1 \text { phase and } \\
3 \text { logical activities }\end{array}$} & \multicolumn{2}{|c|}{$\begin{array}{l}\text { practices are included } \\
\text { and/or negated according } \\
\text { to project requirements }\end{array}$} & --- & \\
\hline [S4] & \multicolumn{7}{|c|}{ Novel Hybrid Model: Integrating Scrum and XP } \\
\hline 2012 & \multicolumn{3}{|l|}{ SCRUM } & \multicolumn{3}{|c|}{ XP } & Goal \\
\hline $\begin{array}{c}\text { Practices } \\
\text { adopted }\end{array}$ & \multicolumn{3}{|c|}{ Follow all formal ceremonies, artifacts, and roles } & \multicolumn{3}{|c|}{$\begin{array}{c}\text { planning phase, designing phase, coding phase, } \\
\text { and testing phase, practices of XP }\end{array}$} & \multirow{2}{*}{$\begin{array}{l}\text { Improved software } \\
\text { quality, client } \\
\text { satisfaction, \& } \\
\text { improved productivity }\end{array}$} \\
\hline $\begin{array}{c}\text { Practices } \\
\text { excluded/modified }\end{array}$ & \multicolumn{3}{|l|}{ Sprint Zero } & \multicolumn{3}{|r|}{-} & \\
\hline [S5] & \multicolumn{7}{|c|}{ Empirical Estimation of Hybrid Model: A Controlled Case Study } \\
\hline 2012 & \multicolumn{2}{|l|}{ RUP } & \multicolumn{2}{|c|}{ SCRUM } & & $\mathrm{XP}$ & Goal \\
\hline $\begin{array}{l}\text { Practices } \\
\text { adopted }\end{array}$ & \multicolumn{2}{|c|}{$\begin{array}{l}4 \text { phases i) inception ii) Elaboration, } \\
\text { iii) Production \& iv) Transition }\end{array}$} & \multicolumn{2}{|c|}{\begin{tabular}{|c|} 
Product \& Sprint backlog, \\
$\begin{array}{c}\text { Sprint, Daily Scrum, Sprint } \\
\text { review, PO, development } \\
\text { team }\end{array}$ \\
\end{tabular}} & $\begin{array}{r}\text { Pair } \mathrm{p} \\
\text { in }\end{array}$ & $\begin{array}{l}\text { rogramming, refactoring, } \\
\text { tegration, unit testing }\end{array}$ & \multirow{2}{*}{$\begin{array}{c}\text { High quality software, } \\
\text { satisfy business \& } \\
\text { customer needs, adapt } \\
\text { to changing } \\
\text { requirements }\end{array}$} \\
\hline \begin{tabular}{c|} 
Practices \\
excluded/modified
\end{tabular} & 6 logical activities & & $\begin{array}{r}\text { Role of Pr } \\
\text { SPRL }\end{array}$ & $\begin{array}{l}\text { roject Manager, } \\
\text { UP Master }\end{array}$ & Anticip & $\begin{array}{l}\text { pation, crafting, execution, } \\
\quad \& \text { assessment }\end{array}$ & \\
\hline [S6] & \multicolumn{7}{|c|}{ IXPRUM- A novel agile model for software development } \\
\hline 2012 & \multicolumn{3}{|l|}{ Scrum } & \multicolumn{3}{|r|}{$\mathrm{XP}$} & Goal \\
\hline $\begin{array}{c}\text { Practices } \\
\text { adopted }\end{array}$ & \multicolumn{3}{|c|}{ All formal Practices of Scrum } & \multicolumn{3}{|c|}{$\begin{array}{l}4 \text { Phases of XP, continuous integration and } \\
\text { testing }\end{array}$} & \multirow{2}{*}{$\begin{array}{l}\text { Improved quality, } \\
\text { productivity }\end{array}$} \\
\hline \begin{tabular}{|c|} 
Practices \\
excluded/modified
\end{tabular} & \multicolumn{3}{|c|}{$\begin{array}{l}\text { Phases of Scrum, Scrum Master as IXPRUM Master, } \\
\text { Project Manager }\end{array}$} & \multicolumn{3}{|c|}{ Rest of the XP practices } & \\
\hline [S7] & \multicolumn{7}{|c|}{ IXSCRUM-A Framework Combining Scrum and XP } \\
\hline 2013 & SCRUM & & & & & $\mathrm{XP}$ & Goal \\
\hline $\begin{array}{l}\text { Practices } \\
\text { adopted }\end{array}$ & $\begin{array}{c}\text { Strictly follow all formal ceremon } \\
\text { roles }\end{array}$ & s, a & artifacts, and & $\begin{array}{r}\text { Test-driven d } \\
\text { developers, test } \\
\mathrm{c}\end{array}$ & $\begin{array}{l}\text { levelopm } \\
\text { ers), unit } \\
\text { onstant } 1\end{array}$ & $\begin{array}{l}\text { nent, XP roles (analysts, } \\
\text { it testing, simple design, \& } \\
\text { refactoring, }\end{array}$ & $\begin{array}{l}\text { Customer satisfaction, } \\
\text { improved product } \\
\text { amlity within } \text { time \& }\end{array}$ \\
\hline \begin{tabular}{c|c|} 
Practices \\
excluded/modified
\end{tabular} & --- & & & Rest of $\mathrm{tl}$ & he XP pr & ractices and phases & cost constraints \\
\hline [S8] & SCXTREME Framework: A Cus & $\operatorname{miz}$ & zed Approach & h of Process Impr & ovement & ts in Agile Blend with CMN & MI Practices in Pakistan \\
\hline 2013 & SCRUM & & $\mathrm{XI}$ & $\mathrm{P}$ & & CMMI & Goal \\
\hline $\begin{array}{l}\text { Practices } \\
\text { adopted }\end{array}$ & $\begin{array}{l}\text { All formal ceremonies, artifacts, } \\
\qquad \& \text { roles }\end{array}$ & & Phases & of XP & $\begin{array}{l}\text { From } \\
\text { From } \\
\end{array}$ & $\begin{array}{l}\text { Level2 [PP, CM, REQM, } \\
\text { PPQA, \& PMC] } \\
\text { Level } 3 \text { [RSKM \& VER] }\end{array}$ & $\begin{array}{c}\text { Improved } \\
\text { organizational } \\
\text { performance, improved }\end{array}$ \\
\hline \begin{tabular}{c|c|} 
Practices \\
excluded/modified
\end{tabular} & --- & & - & - & Rest of & PAs \& SPs of level $2 \& 3$ & $\begin{array}{l}\text { product quality, } \\
\text { customer satisfaction }\end{array}$ \\
\hline [S9] & A Hybrid & Mod & lel by Integra & ating Agile Practic & ces for $\mathrm{P}$ & Pakistani Software Industry & \\
\hline 2014 & SCRUM & & & $\mathrm{XP}$ & & DSDM & Goal \\
\hline $\begin{array}{c}\text { Practices } \\
\text { adopted }\end{array}$ & $\begin{array}{l}\text { Management practices, Roles, } \\
\text { Ceremonies, Artifacts }\end{array}$ & & $\begin{array}{l}\text { Imost all the } \\
\text { Phase }\end{array}$ & $\begin{array}{l}\text { practices of XP, } \\
\text { s of XP }\end{array}$ & $\begin{array}{r}\text { Bus } \\
\text { Fea } \\
\text { Charter } \\
\text { docur }\end{array}$ & $\begin{array}{l}\text { siness Case document, } \\
\text { asibility report, Project } \\
\text { r, Design document, Sprint } \\
\text { ment, Review document, } \\
\text { Risk analysis }\end{array}$ & $\begin{array}{l}\text { Effective management, } \\
\text { quality product, } \\
\text { productivity, }\end{array}$ \\
\hline \begin{tabular}{|c|} 
Practices \\
excluded/modified
\end{tabular} & Role of Technical Writer & & & -- & & DSDM roles & \\
\hline [S10] & Enhance & ent & $s$ in SCRUM & 1 Framework using & g Extrem & ne Programming Practices & \\
\hline 2014 & SCRUM & & & & & XP & Goal \\
\hline $\begin{array}{l}\text { Practices } \\
\text { adopted }\end{array}$ & All roles, ceremonies, and artifa & $\mathrm{s}$ ar & followed & $\begin{array}{l}\text { Pair program } \\
\text { refactoring, } \\
\text { standards, u }\end{array}$ & $\begin{array}{l}\text { nming, c } \\
\text { testing, } \\
\text { user stori } \\
\text { own }\end{array}$ & $\begin{array}{l}\text { continuous integration, } \\
\text { simple design, coding } \\
\text { ies, \& collective code } \\
\text { eership }\end{array}$ & $\begin{array}{l}\text { Quality software, on- } \\
\text { time delivery }\end{array}$ \\
\hline \begin{tabular}{|c|} 
Practices \\
excluded/modified
\end{tabular} & --- & & & Rest of th & he XP pr & ractices and phases & \\
\hline
\end{tabular}




\begin{tabular}{|c|c|c|c|c|c|c|c|}
\hline [S11] & \multicolumn{7}{|c|}{ Software Quality Assurance of Medium Scale Projects by using DXPRUM Methodology } \\
\hline 2014 & \multicolumn{2}{|l|}{ SCRUM } & \multicolumn{3}{|c|}{$\mathrm{XP}$} & DSDM & Goal \\
\hline $\begin{array}{c}\text { Practices } \\
\text { adopted }\end{array}$ & \multicolumn{2}{|c|}{$\begin{array}{l}\text { Most of the ceremonies, roles and } \\
\text { artifacts with slight modifications }\end{array}$} & \multicolumn{3}{|c|}{\begin{tabular}{|c|} 
User story cards, coding \\
standards, test-driven \\
development, pair \\
programming, refactoring, \\
40-hours per week work, \& \\
collective ownership of code \\
\end{tabular}} & $\begin{array}{l}\text { Pre-project \& post-project } \\
\text { phases, feasibility, design, } \\
\text { functional prototype }\end{array}$ & \multirow{2}{*}{$\begin{array}{l}\text { Improved software } \\
\text { quality, in-time } \\
\text { product delivery, \& } \\
\text { reduced cost }\end{array}$} \\
\hline $\begin{array}{c}\text { Practices } \\
\text { excluded/modified }\end{array}$ & \multicolumn{2}{|c|}{$\begin{array}{l}\text { Scrum Master Role is adapted as } \\
\text { DXPRUM Expert, } \\
\text { duration of meetings is elongated; } \\
\text { team size is } 4-7 \text { members }\end{array}$} & \multicolumn{3}{|c|}{$\begin{array}{l}\text { Rest of the XP practices \& } \\
\text { phases of XP }\end{array}$} & DSDM roles & \\
\hline [S12] & \multicolumn{7}{|c|}{ XSR: Novel Hybrid Software Development Model (Integrating XP, Scrum \& RUP) } \\
\hline 2014 & \multicolumn{2}{|l|}{ RUP } & \multicolumn{3}{|c|}{ Scrum } & $\mathrm{XP}$ & Goal \\
\hline $\begin{array}{c}\text { Practices } \\
\text { adopted }\end{array}$ & \multicolumn{2}{|c|}{$\begin{array}{l}\text { 3 Phases of RUP (inception, } \\
\text { construction, transition), artifacts } \\
\text { (vision document, architectural } \\
\text { modeling, risk assessment, } \\
\text { deployment planning) }\end{array}$} & \multicolumn{3}{|c|}{$\begin{array}{l}\text { Roles, few requirement } \\
\text { management Practices e.g. } \\
\text { prioritize items, Sprint }\end{array}$} & $\begin{array}{c}\text { User story cards, coding } \\
\text { standards, test-driven } \\
\text { development, pair programming, } \\
\text { refactoring, collective ownership } \\
\text { of code } \\
\end{array}$ & \multirow{2}{*}{$\begin{array}{c}\text { High Quality software, } \\
\text { on-time delivery, and } \\
\text { less cost, business \& } \\
\text { customer needs } \\
\text { satisfaction, team's } \\
\text { productivity }\end{array}$} \\
\hline $\begin{array}{c}\text { Practices } \\
\text { excluded/modified }\end{array}$ & \multicolumn{2}{|l|}{$\begin{array}{l}\text { Elaboration phase, } \\
6 \text { logical activities }\end{array}$} & \multicolumn{3}{|c|}{$\begin{array}{c}\text { Sprint zero, No Scrum } \\
\text { Master Role, } \\
\text { All Sprints are of same } \\
\text { duration, \& artifacts } \\
\end{array}$} & $\begin{array}{c}\text { Rest of the XP practices \& phases } \\
\text { of XP }\end{array}$ & \\
\hline [S13] & \multicolumn{7}{|c|}{ US-Scrum: A Methodology for Developing Software with Enhanced Correctness, Usability and Security } \\
\hline 2015 & \multicolumn{3}{|l|}{ SCRUM } & \multicolumn{3}{|r|}{ FDD } & Goal \\
\hline $\begin{array}{c}\text { Practices } \\
\text { adopted }\end{array}$ & \multicolumn{3}{|c|}{$\begin{array}{l}\text { User stories, use scenarios Product Backlog, } \\
\text { Sprint, Sprint Backlog, Scrum meetings, }\end{array}$} & \multicolumn{3}{|c|}{ Identification of Features, Build, User Acceptance } & \multirow{2}{*}{$\begin{array}{l}\text { User satisfaction, } \\
\text { team's productivity, } \\
\text { enhanced quality }\end{array}$} \\
\hline \begin{tabular}{c|} 
Practices \\
excluded/modified
\end{tabular} & \multicolumn{3}{|c|}{\begin{tabular}{|c|} 
Multiple Scrum Masters for Functional ,Security, \\
Usability, Multiple Teams, artifacts(abuser stories, \\
abuser scenarios)
\end{tabular}} & \multicolumn{3}{|c|}{$\begin{array}{l}\text { Multiple feature lists: Functional, Security, } \\
\text { Usability feature lists. }\end{array}$} & \\
\hline [S14] & \multicolumn{7}{|c|}{ A Hybrid Agile model using Scrum and Feature Driven Development } \\
\hline 2016 & \multicolumn{3}{|l|}{ SCRUM } & \multicolumn{3}{|r|}{$\begin{array}{l}\text { FDD } \\
\end{array}$} & Goal \\
\hline $\begin{array}{c}\text { Practices } \\
\text { adopted }\end{array}$ & \multicolumn{3}{|c|}{$\begin{array}{c}\text { Roles, artifacts, Daily Scrum, Backlog } \\
\text { Reinforcement, code integration, Release, Sprint }\end{array}$} & \multicolumn{3}{|c|}{$\begin{array}{l}\text { Identification of Features, Build, QA, Release, } \\
\text { Inspection }\end{array}$} & \multirow{2}{*}{\begin{tabular}{|c|} 
Improved quality \\
product, timely \\
delivery, \& customer \\
satisfaction \\
\end{tabular}} \\
\hline $\begin{array}{c}\text { Practices } \\
\text { excluded/modified } \\
\end{array}$ & \multicolumn{3}{|c|}{ Rest of the practices } & & & FDD roles & \\
\hline [S15] & A S & ynch & onous Agile $\mathrm{F}_{\mathrm{I}}$ & Framework P & ropos & sal Combining Scrum and TDD & \\
\hline 2016 & SCRUM & & & & & TDD & Goal \\
\hline \begin{tabular}{|c|}
$\begin{array}{c}\text { Practices } \\
\text { adopted }\end{array}$ \\
\end{tabular} & $\begin{array}{r}\text { Scrum Master, developer, dai } \\
\text { review and retrospectiv }\end{array}$ & $\begin{array}{l}\text { ly Scl } \\
\text { e eval }\end{array}$ & $\begin{array}{l}\text { 1, Sprints, } \\
\text { ion }\end{array}$ & $\begin{array}{r}\text { Developer, } \\
\text { feedback, }\end{array}$ & $\begin{array}{l}\text { test a } \\
\text { form }\end{array}$ & $\begin{array}{l}\text { and develop, test suits, continuous } \\
\text { al tests, code quality, Test cycles }\end{array}$ & $\begin{array}{c}\text { Improved software } \\
\text { quality \& project }\end{array}$ \\
\hline \begin{tabular}{c|} 
Practices \\
excluded/modified
\end{tabular} & Rest of practic & & & & & Rest of practices & $\begin{array}{c}\text { management, reduced } \\
\text { time and cost }\end{array}$ \\
\hline [S16] & Progress of agile movements in & $\mathrm{A}$ & alia: Propose a & $\begin{array}{r}\text { a Universal I } \\
\text { frame }\end{array}$ & $\begin{array}{l}\text { Dynan } \\
\text { ework }\end{array}$ & $\begin{array}{l}\text { mic System Development Method ( } \\
\text { k }\end{array}$ & UDSDM) and universal \\
\hline 2016 & SCRUM & & XP & & & DSDM & Goal \\
\hline $\begin{array}{c}\text { Practices } \\
\text { adopted }\end{array}$ & $\begin{array}{c}\text { Daily Scrum, Sprint planning, } \\
\text { Sprint, Sprint Review, product } \\
\text { Backlog }\end{array}$ & $\begin{array}{r}\mathrm{P} \\
\text { in } \\
\mathrm{Me} \\
\text { own }\end{array}$ & $\begin{array}{l}\text { ir programmin } \\
\text { egration, Simp } \\
\text { aphor, Refacto } \\
\text { rship, coding } \\
\text { of X }\end{array}$ & $\begin{array}{l}\mathrm{ng} \text {, continuou } \\
\text { ple Design, } X \\
\text { oring, collect } \\
\text { standard, ph } \\
\mathrm{XP}\end{array}$ & & $\begin{array}{l}\text { Framework of controls, daily } \\
\text { tracking of progress, team } \\
\text { collaboration }\end{array}$ & $\begin{array}{l}\text { Customer satisfaction, } \\
\text { response to change, } \\
\text { team collaboration }\end{array}$ \\
\hline $\begin{array}{c}\text { Practices } \\
\text { excluded/modified } \\
\end{array}$ & --- & & - & & & $\begin{array}{l}\text { Management practices \& } \\
\text { Engineering practices } \\
\end{array}$ & \\
\hline$[S 17]$ & & egrati & a RUP Appro & oach with Ag & ile M & Method for Large Scale Projects & \\
\hline 2017 & RUP & & SCRUM & & & $\mathrm{XP}$ & Goal \\
\hline $\begin{array}{l}\text { Practices } \\
\text { adopted }\end{array}$ & $\begin{array}{c}9 \text { disciplines of RUP, and } 4 \\
\text { Phases of RUP (inception, } \\
\text { elaboration, construction, } \\
\text { transition) } \\
\end{array}$ & & $\begin{array}{r}\mathrm{m} \text { roles, cerem } \\
\text { artifacts }\end{array}$ & nonies, and & $\begin{array}{l}\text { Plan } \\
\text { XP, } \\
\end{array}$ & $\begin{array}{l}\text { n, design, code, and test activity of } \\
\text {, user stories, } 40 \text {-hours work week, } \\
\text { coding standard }\end{array}$ & $\begin{array}{l}\text { High quality product, } \\
\text { \& improved team }\end{array}$ \\
\hline $\begin{array}{c}\text { Practices } \\
\text { excluded/modified } \\
\end{array}$ & 6 logical activities & & --- & & & $\begin{array}{l}\text { st of the XP practices \& phases of } \\
\text { XP }\end{array}$ & \\
\hline$[\mathrm{S} 18]$ & & & Comparati & ive analysi & f DS & DM \& DXPRUM & \\
\hline
\end{tabular}




\begin{tabular}{|c|c|c|c|}
\hline 2017 & DSDM & DXPRUM & Goal \\
\hline $\begin{array}{c}\text { Practices } \\
\text { adopted }\end{array}$ & All the practices without any modification & $\begin{array}{c}\text { Practices from Scrum, XP, \& DSDM as discussed } \\
\text { in [S11] }\end{array}$ & $\begin{array}{c}\text { Improved software } \\
\text { quality, customer } \\
\text { involvement, reduced } \\
\text { time and cost }\end{array}$ \\
\hline $\begin{array}{c}\text { Practices } \\
\text { excluded/modified }\end{array}$ & --- & --- & \begin{tabular}{c}
--- \\
\hline
\end{tabular}
\end{tabular}

\section{CONCLUSION}

Hybrid methodologies are always a better choice to opt for, as they offer flexibility to use best practices for any aspect of a software development endeavor. A Systematic Mapping Study (SMS) has been conducted to acquire an overview of existing studies on the integration of Scrum framework with other Agile models. Eighteen articles, published during 2011-2017, were identified through rigorous search. We got a comprehensive insight of the above-mentioned domain and drawn main conclusions which are as follows:

1) Most of the researches contributed in this domain are from academia.

2) $83 \%$ of the total studies were found in journals, rest of the $17 \%$ were published in conference proceedings.

3) Researchers made multiple efforts to integrate $\mathrm{XP}$, FDD, TDD, DSDM, and RUP with Scrum. No researches were found for Kanban and Crystal methods in this context.

4) The number of studies published on integration of Scrum with other Agile models was maximum in 2012 and 2014, same is expected in 2017.

5) Research focus was found to be more inclined towards combining XP and Scrum. Hybrids of Scrum with XP remained prevalent throughout researches. About $83 \%$ of the total studies found were based on integration of Scrum and XP.

6) The second highest trend was combination of Scrum and DSDM. It is observed that DSDM has never been blended with Scrum alone, but, needed XP to work with.

7) Other Agile models TDD and FDD are now gaining attention of researchers for making hybrids.

8) Being iterative, and incremental, the RUP gained significant attention.

9) About $47 \%$ of the total studies found, were proposals, $42 \%$ validations, and $11 \%$ were based on evaluations.

10) The goals achieved by most of the case-studies were: productivity, Quality, customer satisfaction, reduction in cost, team motivation, and on-time delivery.

11) About $67 \%$ of the researches adopted almost all the artifacts, roles, ceremonies, and practices of Scrum in hybrid models. Rest of them either partially adapted and/or excluded practices of Scrum.

12) About $56 \%$ of the studies adopted maximum engineering practices from XP, $17 \%$ adopted partially, while, rest of $27 \%$ mostly adapted/ excluded practices and phases.

13) Practice of training for team members was found effective in almost all case-studies.

Scarcity of validation and evaluation researches call for more empirical studies conducted with more pragmatic evidence on integration of Scrum within Agile family, in industrial settings to generalize the results. A joint venture of academia and industry is rigorously needed to identify more systematic strategies for combining Agile development approaches within a specific context.

\section{APPENDiX A. SELECTED PRIMARY STUdieS}

[S1]V.E. Jyothi, and K.N. Rao, " Effective Implementation of Agile Practices: Ingenious and Organized Theoretical Framework," In IJACSA) International Journal of Advanced Computer Science and Applications, 2011

[S2]M.R.J. Qureshi, " Empirical Evaluation of the Proposed eXSCRUM Model: Results of a Case Study," International Journal of Computer Science Issues IJCSI Vol. 8, Issue 3, No. 2, May 2011.

[S3]M. S. Bashir, and M. R. J. Qureshi, "Hybrid Software Development Approach for Small to Medium Scale Projects: RUP, XP \& Scrum," Sci. Int. (Lahore), Vol.24, No.4, pp. 381-384, 2012.

[S4]Z. Mushtaq, and M. R. J. Qureshi, "Novel Hybrid Model: Integrating Scrum and XP,' I.J. Information Technology and Computer Science, No. 6, pp. 39-44, 2012

[S5]S. U. Nisa, and M. R. J. Qureshi, "Empirical Estimation of Hybrid Model: A Controlled Case Study," I.J. Information Technology and Computer Science, Vol. 4, No. 8, pp. 43-50, 2012.

[S6]A. Ullah, G. Rasool, and M.R.J. Qureshi, "IXPRUM-A novel agile model for software development," AWER Procedia Information Technology and Computer Science, Vol.1, No.1, pp.1314-1320, 2012

[S7]Chhavi Malhotra, and Anuradha Chug, "IXSCRUMA Framework Combining Scrum and XP", International Journal of Scientific \& Engineering Research, Vol. 4, Issue 7, July-2013.

[S8] Samina Jan, Ali Javed,"SCXTREME Framework: A Customized Approach of Process Improvements in Agile Blend with CMMI Practices in Pakistan," International Journal of Information Technology and Computer Science (IJITCS), Vol.5, No.3, pp. 69-78, 2013.

[S9] S. Sultana, Y.H. Motla, S. Asghar, M. Jamal, and R. Azad, "A hybrid model by integrating agile practices for Pakistani software industry," In Electronics, Communications and Computers (CONIELECOMP), 
2014 International Conference on (pp. 256-262). IEEE, February 2014

[S10] N.R. Darwish, "Enhancements In Scrum Framework Using Extreme Programming Practices," International Journal of Intelligent Computing and Information Sciences (IJICIS), Ain Shams University, Vol. 14, No.2, pp. 53-67, 2014

[S11] M. Fahad, S. Qadri, S.S. Muhammad, and M. Husnain, "Software Quality Assurance of Medium Scale Projects by using DXPRUM Methodology," International Journal of Natural and Engineering Sciences (IJNES'14).(Turkey), Vol.8, No.1 , pp. 42-48, 2014

[S12] G. Ahmad, T.R. Soomro, and M.N. Brohi," XSR: Novel Hybrid Software Development Model (Integrating XP, Scrum \& RUP)," International Journal of Soft Computing and Engineering (IJSCE), Vol. 2, No. 3, pp. 126-130,2014

[S13] U. Rafi, T. Mustafa, N. Iqbal, and W.U.I. Zafar, "US-Scrum: A Methodology for Developing Software with Enhanced Correctness, Usability and Security," International Journal of Scientific \& Engineering Research, Vol. 6, No. 9, p.377, 2015

[S14] S.S. Tirumala, S. Ali, B.G. Anjan, "A Hybrid Agile model using SCRUM and Feature Driven Development," International Journal of Computer Applications Vol. 156 pp. 1-5, 2016.

[S15] M.M Savoine, V.F. Rocha, C.A.C. Bezerra, A.M.C.de Araújo, and J.K.M. Matias, "A Synchronous Agile Framework Proposal Combining Scrum and TDD," ICSEA, p. 350, 2016

[S16] H.M. Tri, A. Alsadoon, P.W.C. Prasad, and A. Elchouemi, "Progress of agile movements in Australia: Propose a Universal Dynamic System Development Method (UDSDM) and universal framework," In Information and Communication Systems (ICICS), 2016 7th International Conference on (pp. 282-285). IEEE, April 2016

[S17] N.R. Darwish, and A.A.M. Warad, "Integrating RUP Approach with Agile Method for Large Scale Projects," Software Engineering and Technology, Vol. 9, No.5, pp. 85-90, 2017

[S18] Fahad, M., Qadri, S., Ullah, S., Husnain, M., Qaiser, R., Ahmed, S., Qureshi, W.A. and Muhammad, S.S., 2017. A Comparative Analysis of DXPRUM and DSDM. IJCSNS, 17(5), p.259.

\section{REFERENCES}

[1] J. A. Highsmith, "Agile software development ecosystems," vol. 13, Addison-Wesley Professional, 2002.

[2] A. Alliance. 2001 "Agile manifesto," [Online]. Available: http://agilemanifesto.org/ [Accessed 2505 2017]

[3] K. Beck, M. Beedle, A. Van Bennekum, A. Cockburn, W. Cunningham, M. Fowler, J. Grenning, J. Highsmith, A. Hunt, R. Jeffries, and J. Kern, "Manifesto for agile software development," 2001.

[4] P. Diebold, and M. Dahlem. "Agile practices in practice: A mapping study," In International Conference on Evaluation and Assessment in Software Engineering, EASE '14, pages 30:1-30:10, New York, NY, USA, 2014. ACM.
[5] T. Dyba, and T. Dingsøyr, "Empirical studies of agile software development: A systematic " review," Information and Software Technology, Vol.50, No. 9-10 pp.833 - 859, 2008.

[6] T. Dingsøyr, S. Nerur, V. Balijepally, and N. B. Moe, "A decade of agile methodologies: Towards explaining agile software development," Journal of Systems and Software, Vol.85, No.6 pp.1213- 1221, 2012. Special Issue: Agile Development.

[7] S. Ashraf, S. Aftab, "IScrum: An Improved Scrum Process Model", International Journal of Modern Education and Computer Science (IJMECS), Vol.9, No.8, pp.16-24, 2017.

[8] K. Schwaber, A. Beedle, "Agile Software Development with SCRUM," Prentice-Hall, Upper Saddle River. NJ, 2002.

[9] K. Beck, "Test-driven development: by example," Addison-Wesley Professional, 2003

[10] S.R. Palmer, and M. Felsing, "A practical guide to feature-driven development," Pearson Education, 2001

[11] K. Beck, " Extreme Programming Explained," Addison Wesley, Reading, MA, 1999

[12] J. Stapleton, "DSDM, dynamic systems development method: the method in practice," Cambridge University Press, 1999

[13] S. Sharma, and N. Hasteer, "A comprehensive study on state of Scrum development," In Computing, Communication and Automation (ICCCA), 2016 International Conference on, pp. 867-872, IEEE, April 2016.

[14] B. Murphy, C. Bird, T. Zimmermann, L. Williams, N. Nagappan, and A. Begel, 2013, October. "Have agile techniques been the silver bullet for software development at Microsoft?" In Empirical Software Engineering and Measurement, 2013 ACM/IEEE International Symposium on (pp. 75-84). IEEE.

[15] A. Komus, M. Kuberg, C. Atinc, L. Franner, F. Friedrich, T. Lang, A. Makarova, D. Reimer, and J. Pabst. Status quo agile 2014, 2014.

[16] VersionOne. State of agile survey. Available from: http://www.versionone.com/ agile-resources/moreresources/blogs/, 2006-2014. [Accessed 0506 2017]

[17] M. Kuhrmann, P., Diebold, J. Münch, P. Tell, V. Garousi, M. Felderer, K. Trektere, F. McCaffery, O. Linssen, E. Hanser, and Prause, "Hybrid software and system development in practice: waterfall, scrum, and beyond," In Proceedings of the 2017 International Conference on Software and System Process (pp. 30-39). ACM, C.R., July 2017

[18] K. Schwaber, G. Laganza, D. D’Silva, "The Truth about Agile Processes: Frank Answers to Frequently Asked Questions," Forrester Report, 2007.

[19] T. Chow, D. Cao, "A survey study of critical success factors in agile software projects," Journal of Systems and Software Vol.81, pp.961-971, 2008

[20] A. Sillitti, M. Ceschi, B. Russo, G. Succi, "Managing uncertainty in requirements: a survey in documentationdriven and agile companies," in: Proceedings of 11th IEEE International Symposium on Software Metrics, 2005.

[21] A.S. Campanelli, and F.S. Parreiras, "Agile methods tailoring-A systematic literature review. Journal of Systems and Software, " No. 110, pp.85-100, 2015

[22] D. West, "Water-Scrum-Fall is the reality of agile for most organizations today," Technical report, Forrester, 2011.

[23] G. Theocharis, M. Kuhrmann, J. Münch, and P. Diebold, "Is water-scrum-fall reality? on the use of agile and 
traditional development practices," In International Conference on Product-Focused Software Process Improvement, Springer International Publishing, pp.149166, December 2015

[24] E.S. Cardozo, J.B.F.A. Neto, A. Barza, A.C.C França, and F.Q. da Silva, "SCRUM and Productivity in Software Projects: A Systematic Literature Review," In EASE, April 2010

[25] J. López-Martínez, R. Juárez-Ramírez, C. Huertas, S. Jiménez, and C. Guerra-García," Problems in the Adoption of Agile-Scrum Methodologies: A Systematic Literature Review," In Software Engineering Research and Innovation (CONISOFT), 2016 4th International Conference in IEEE, pp.141-148, April 2016

[26] P. Diebold, and M. Dahlem, " Agile practices in practice: a mapping study," In Proceedings of the 18th International Conference on Evaluation and Assessment in Software Engineering ACM, p.30, May 2014

[27] S. Ashraf, S. Aftab, "Latest Transformations in Scrum: A State of the Art Review", International Journal of Modern Education and Computer Science (IJMECS), Vol.9, No.7, pp.12-22, 2017.

[28] N. Kurapati, V.S.C. Manyam, and K. Petersen, " Agile software development practice adoption survey," Agile processes in software engineering and extreme programming, pp.16-30, 2012

[29] X. Wang, K. Conboy, and O. Cawley, " "Leagile" software development: An experience report analysis of the application of lean approaches in agile software development," Journal of Systems and Software, Vol.85, No. 6, pp.1287-1299, 2012

[30] H. Holmström, B. Fitzgerald, P.J. Ågerfalk, and E.O. Conchúir, " Agile practices reduce distance in global software development," Information systems management, Vol. 23, No.3, pp.7-18, 2006

[31] R.R. Raval, and H.M. Rathod, "Improvements in Agile Model using Hybrid Theory for Software Development in Software Engineering," International Journal of Computer Applications, Vol.90, No.16, 2014

[32] B. Kitchenham, S. Charters," Guidelines for performing systematic literature reviews in software engineering," EBSE Technical Report, Keele University, 2007

[33] E. Engström, and P. Runeson, "Software product line testing-a systematic mapping study. Information and Software Technology," Vol.53, No.1, pp.2-13, 2011

[34] K. Petersen, R. Feldt, S. Mujtaba, M. Mattsson, "Systematic mapping studies in software engineering," in: 12th International Conference on Evaluation and Assessment in Software Engineering (EASE), University of Bari, Italy, Vol. 8, pp. 68-77 26-27, June 2008.

[35] S. Jalali, and C. Wohlin, "Systematic literature studies: database searches vs. backward snowballing," In Proceedings of the ACM-IEEE international symposium on Empirical software engineering and measurement pp. 29-38, ACM, September 2012

[36] E. M. Schön, J. Thomaschewski, and M. J. Escalona, "Agile Requirements Engineering: A systematic literature review," Computer Standards \& Interfaces, Vol. 49, pp.79-91, 2017.

[37] V. Alves, N. Niu, C. Alves, and G. Valença, "Requirements engineering for software product lines: A systematic literature review," Information and Software Technology, Vol.52, No. 8, pp.806-820, 2010

[38] M. Shahin, P. Liang, and M.A. Babar, "A systematic review of software architecture visualization techniques," Journal of Systems and Software, Vol.94, pp.161-185, 2014

[39] R. Wieringa, N. Maiden, N. Mead, C. Rolland," Requirements engineering paper classification and evaluation criteria: a proposal and a discussion," Requirements Engineering, Vol.11, No. 1, pp. 102-107, 2006.

[40] P. Brereton, B.A. Kitchenham, D. Budgen, M. Turner, and M. Khalil, "Lessons from applying the systematic literature review process within the software engineering domain," Journal of systems and software, Vol. 80 No. 4, pp. 571-583, 2007.

[41] M. Staples, and M. Niazi, "Experiences using systematic review guidelines," Journal of Systems and Software, Vol.80, No.9, pp.1425-1437, 2007

[42] V. Mahnic, "Improving Software Development through Combination of Scrum and Kanban," Recent Advances in Computer Engineering, Communications and Information Technology, Espanha 2014.

[43] https://www.scrumalliance.org/why-scrum/state-ofscrum-report/2016-state-of-scrum [Accessed 0206 2017]

[44] F. Anwer, S. Aftab, S. S. M. Shah, and U. Waheed, "Comparative Analysis of Two Popular Agile Process Models: Extreme Programming and Scrum," International Journal of Computer Science and Telecommunications, vol. 8, no. 2, March 2017.

\section{Authors' Profiles}

Sara Ashraf is a student of MS Computer Science with specialization in Software Engineering at Virtual University of Pakistan. Her areas of interest include Agile Development Models and Software Process Improvement.

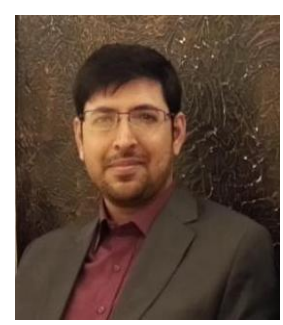

Shabib Aftab received MS Degree in Computer Sciences from COMSATS Institute of Information Technology Lahore, Pakistan. He is serving as a Lecturer Computer Sciences at Virtual University of Pakistan. His research areas include Data Mining and Software Process Improvement.

How to cite this paper: Sara Ashraf, Shabib Aftab, "Scrum with the Spices of Agile Family: A Systematic Mapping", International Journal of Modern Education and Computer Science(IJMECS), Vol.9, No.11, pp. 58-72, 2017.DOI: 10.5815/ijmecs.2017.11.07 